\title{
A Study on Correlation between Anxiety Symptoms and Suicidal Ideation
}

\author{
Hee-Yeon Choi', Soo-In Kim ${ }^{1}$, Kyu Wol Yun ${ }^{1}$, Young Chul Kim¹, \\ Weon-Jeong Lim ${ }^{1}$, Eui-Jung $\mathrm{Kim}^{1}$ and Jae-Hong Ryoo ${ }^{2}$ \\ 1 Department of Psychiatry, Ewha Womans University School of Medicine, Seoul, Korea \\ ${ }^{2}$ Department of Occupational Medicine, Kangbuk Samsung Hospital, Sungkyunkwan University, School of Medicine, Seoul, Korea
}

Objective In South Korea, the number of deaths from suicide has increased in the last two decades, and suicide has become both a social and political problem. In this study, after controlling the variables influencing suicidal ideation, it was expected that it would be determined if anxiety symptoms are independently related to suicidal ideation.

Methods Data were obtained from 327 psychiatric outpatients accomplished a self-reported questionnaire that included sociodemographic characteristics and clinical variables as well as self-rating scales for measuring the severity of one's anxiety, depression, and suicidal ideation. Logistic-regression analyses were used to determine the correlation between anxiety symptoms and significant suicidal ideation, adjusting for covariates.

Results The patients with significant suicidal ideation were shown to be less educated, unemployed, never married, divorced, or separated by death, or living alone, and were shown to have a lower income, a drinking habit, a higher number of past suicide attempts, and more family members who committed suicide, than the patients without significant suicidal ideation. After adjusting the covariates influencing significant suicidal ideation, anxiety symptoms were associated with significant suicidal ideation. However, after adjusting for depressive symptoms, only the trait anxiety was associated with significant suicidal ideation.

Conclusion These findings suggest that anxiety symptoms are an independent risk factor for suicidal ideation. Clinicians may thus use anxiety symptoms for the screening examination when evaluating suicidal ideation and risk, and will have to actively evaluate and treat the anxiety symptoms of patients with suicidal tendencies.

Psychiatry Investig 2011;8:320-326

Key Words Suicidal ideation, Anxiety, Correlates.

\section{INTRODUCTION}

In Korea, the number of deaths from suicide has increased during the last two decades. Suicide was the tenth leading cause of death in 1992, and by 2009, it had risen to fourth place, accounting for 15,413 deaths per year. ${ }^{1}$ What is more, as of 2009, the lifetime prevalence of suicidal ideation, plans, and attempts in Korea were 15.2\%, 3.3\%, and 3.2\%, respectively. ${ }^{2}$ Suicide has become not only a major public health problem but also a social and political one. Moreover, it is an-

Received: December 30, 2010 Revised: April 26, 2011

Accepted: May 12, 2011 Available online: December 8, 2011

$\triangle$ Correspondence: Soo-In Kim, MD, PhD

Department of Psychiatry, Ewha Womans University School of Medicine, 9111 Mokdong, YangCheon-gu, Seoul 158-710, Korea

Tel: +82-2-2650-2821 , Fax: +82-2-2650-5164, E-mail: 72sooik@ewha.ac.kr

(a) This is an Open Access article distributed under the terms of the Creative Commons Attribution Non-Commercial License (http://creativecommons.org/licenses/bync/3.0) which permits unrestricted non-commercial use, distribution, and reproduction in any medium, provided the original work is properly cited. ticipated that suicide will grow in importance as a burden of disease and a cause of global mortality. ${ }^{3,4}$ Considering that it tends to be hidden or misclassified as a cause of death, the rate of suicide is actually higher than the reported. ${ }^{5}$ Given the seriousness of this issue, numerous studies have tried to evaluate the risk factors of suicide. Above all, an assessment of suicidal ideation is crucial in understanding and preventing suicide. $^{6}$

Psychiatric symptoms and diseases are major risk factors for suicidal ideation. ${ }^{7}$ With a lifetime prevalence of up to $29 \%$, anxiety disorders are the most prevalent psychiatric disorders. ${ }^{8}$ They reduce markedly the quality of life, tend to be chronic, can be disabling, and increase mortality., ${ }^{9,10}$ Many studies note that anxiety disorders are independent risk factors for suicidal ideation ${ }^{11-13}$ and suicidal attempts, ${ }^{14}$ but others suggest that this association increases for those with psychiatric comorbidities. ${ }^{15-17}$ In a Korean nationwide study, suicidal ideation was most strongly associated with obsessive- 
compulsive disorder and also with other anxiety disorders. ${ }^{2}$

Anxiety symptoms may occur in cases that do not meet the full criteria for anxiety disorders, ${ }^{18}$ and these frequently exist in individuals with other or without mental illnesses. ${ }^{19}$ Previous studies have shown that anxiety symptoms are a risk factor for suicide. Diefenbach et al. ${ }^{20}$ found that self-reported anxiety symptoms were associated with suicidality after controlling for confounding factors such as demographics, depressive symptoms, and diagnoses. Ghaziuddin et al. ${ }^{21}$ reported that anxiety independently predicted suicidal ideation among inpatient adolescents. Similarly, Weitoft et al..$^{22}$ indicated that self-reported 'nervousness, uneasiness, and anxiety' in longitudinal follow-up studies were strongly related to subsequent suicide attempts and apparently with later risks for mortality. On the basis of the review of charts of patients who had committed suicide, Busch et al., ${ }^{23}$ indicated that $79 \%$ of the patients showed severe anxiety and/or severe agitation one week prior to suicide. Finally, Fawcett ${ }^{24}$ suggested that impulsiveness, severe anxiety, panic attacks, and agitation comorbid with depression were often immediate suicide risk factors. As previous studies indicated, anxiety symptoms must be considered when evaluating the risk of suicide. However, most previous studies of this issue have focused on suicide attempts or committed suicide. Therefore, few studies have examined the independent role of anxiety symptoms in suicidal ideation independently.

This study aimed to determine the correlations between anxiety symptoms and suicidal ideation. In pursuing this purpose, we used the self-reporting of outpatients to examine suicidal ideation and the various factors that influence it, such as socio-demographic factors, clinical variables, and depressive symptoms. After controlling for these factors, we expected to find that anxiety symptoms are independently related to suicidal ideation.

\section{METHODS}

\section{Subjects}

The study participants were 327 outpatients between 18 and 65 years of age who visited the psychiatry department of Ewha Womans University Mokdong Hospital from July 28, 2009 to October 7, 2009. This study was approved by the Institutional Review Board, and all patients gave their written informed consent after an explanation of its purpose.

\section{Measures}

In outpatient clinics, two psychiatrists explained the purpose of the study to patients, and obtained their informed consent. They investigated the socio-demographic factors (age, gender, marital status, living with family, education, em- ployment, religion, and income) and clinical variables (drinking, smoking, past medical illnesses, psychiatric admissions or suicide attempts, and family mental disorders, including incidences of suicide). Finally, they distributed a self-rating scale questionnaire to the patients, which was completed under a psychiatrist's guidance. These self-rating scales measured the severity of anxiety and depressive symptoms and suicidal ideation.

Severity of anxiety was assessed with the 21-item self-reporting Beck Anxiety Inventory (BAI) of Beck et al. ${ }^{25}$ and the State-Trait Anxiety Inventory (STAI) of Spielberger. ${ }^{26}$ BAI is a carefully constructed measure of anxiety that avoids confusing this disorder with depression. And it reflects state anxiety and current psychopathology rather than stable personality characteristics. ${ }^{27}$ In this study, the Korean translation of the BAI by Yook et al. ${ }^{27}$ was used. STAI consists of separate 20item self-reporting rating scales for measuring state and trait anxiety. The state anxiety scale requires people to describe how they feel in the present. State anxiety scores increase in response to situational stress and decline under relaxed conditions. The trait anxiety scale asks people to indicate how they generally feel. Trait anxiety scores reflect relatively stable individual differences in anxiety proneness that are impervious to situational stress. This study used the Korean translation of the STAI of Kim. ${ }^{28}$ The severity of depressive symptoms was assessed by the 21-item Beck Depression Inventory (BDI), ${ }^{29}$ translated in Korean by Lee et al. ${ }^{30}$ Suicidal ideation was evaluated with the Beck scale for Suicidal Ideation (BSI), ${ }^{31}$ which is composed of 19-item self-questions that measure thoughts and behaviors related to suicide. Previous studies have found that the BSI is the best assessor of preexisting suicidal risk. ${ }^{32}$ The Korean translation of the BSI by Shin ${ }^{33}$ was used in this study. Each diagnosis was made according to the DSM-IV-TR by reviewing charts.

\section{Statistical analysis}

As there was no strict cut-off value of BSI, the participants were divided into two groups: 121 samples with BSI scores of 9 or above were classified as the significant suicidal ideation group and 206 samples with BSI scores under 9 as the no significant suicidal ideation group. A BSI score of 9 was used as a criterion, based on the previous study by Shin. ${ }^{33}$ The incidence of suicidal ideation is substantially greater at a score of 9 or above, and this criterion has widely used in clinical practice for evaluating suicidal ideation in Korea.

First, we examined the risk factors for significant suicidal ideation by comparing the two groups. Chi-square analyses or Fisher's exact test were used for categorical variables and the independent t-test for the comparison of continuous variables. Second, to assess the correlation between anxiety and 
suicidal ideation, we conducted three sets of logistic regression analyses: unadjusted; adjusted for socio-demographics data, and clinical variables; and adjusted for socio-demographics data, clinical variables, and depressive symptoms. A separate logistic regression was performed for each anxiety measure. The statistical level was $\mathrm{p}<0.05$, and all statistical analyses were conducted through SPSS 17.0 version.

\section{RESULTS}

The average age of individuals with significant suicidal ideation was $37.07(\mathrm{SD}=13.18)$, while that of individuals without it was $40.19(\mathrm{SD}=12.16)$. In addition, persons with significant suicidal ideation had less education $(\mathrm{p}=0.0275)$, lower incomes ( $\mathrm{p}=0.0132)$, and greater unemployment $(\mathrm{p}=0.0102)$; were more likely to never have been married, divorced, or separated from partner by death $(\mathrm{p}=0.0232)$; and were more prone to live alone ( $\mathrm{p}=0.0273)$ and to drinking $(\mathrm{p}=0.0402)$ than those without significant suicidal ideation. They also had a higher number of past suicide attempts $(\mathrm{p}<0.0001)$ and more family members who committed suicide $(\mathrm{p}=0.0069)$ than individuals without significant suicidal ideation. However, there was no significant difference between these two groups in terms of gender, religion, medical illness, smoking, past psychiatric admission history, and family history of mental disorders (Table 1).

The most common Axis I diagnosis, evident in 112 (34.3\%) of the individuals, was a mood disorder (major depressive disorder $=80$, dysthymic disorder $=1$, depressive disorder NOS=10, bipolar I disorder=14, bipolar II disorder $=6$, mood disorder NOS $=1$ ). The second one was a anxiety disorder, evident in $75(30 \%)$ of the samples (panic disorder with or without agoraphobia $=35$, obsessive-compulsive disorder $=2$, posttraumatic stress disorder $=5$, generalized anxiety disorder $=9$, anxiety disorder NOS=24) and patients with psychotic disorder were 71 (21.7\%). Nine patients (2.8\%) suffered from Axis II disorder (schizoid personality disorder=1, borderline personality disorder $=6$, histrionic personality disorder $=1$, antisocial personality disorder $=1$ ).

The average BAI score was $19.95(\mathrm{SD}=14.52)$ and the average STAI score was $50.78(\mathrm{SD}=14.19)$ for state anxiety and $50.47(\mathrm{SD}=12.54)$ for trait anxiety. The average BDI score was $18.23(\mathrm{SD}=13.47)$ and the average $\mathrm{BSI}$ score was $7.87(\mathrm{SD}=$ 8.54).

As significant suicidal ideation (BSI scores of 9 or above) increased, so did the severity of depressive symptoms (OR= $1.106 ; 95 \%$ CI 1.080 to 1.133 ). The increase of significant suicidal ideation was associated with more severe anxiety symptoms (BAI: OR=1.071; 95\% CI 1.051 to 1.092, STAI-state: $\mathrm{OR}=1.080$; $95 \%$ CI 12.058 to 1.103 , STAI-trait: $\mathrm{OR}=1.111$;
95\% CI 1.082 to 1.141). Even after adjusting for covariates influencing significant suicidal ideation, such as age, education, employment, marital status, and so on, anxiety symptoms were a risk factor for significant suicidal ideation (Table 2: Model 2). However, after adjusting for depressive symptoms together, only trait anxiety was associated with this tendency (Table 2: Model 3).

\section{DISCUSSION}

This study demonstrates that anxiety symptoms were an independent risk factor for suicidal ideation, after adjusting for other variables such as socio-demographic characteristics, medical and psychiatric illnesses, and depressive symptoms.

Suicidal ideation was higher with younger patients. This finding corresponds to that of previous investigations, which indicate that the risk of the first onset of suicidal ideation increased sharply during adolescence and young adulthood ${ }^{7}$ and that suicidal ideation and suicide attempts were more prevalent among the young. ${ }^{34,35}$ The risk factors for significant suicidal ideation include unemployment, less education, and low-income, which were already identified in previous studies. ${ }^{35,36}$ It may be that social disadvantages result in a lower quality of life, thus lowering individual satisfaction and decreasing the capacity to cope with stress. As in earlier studies, we found that patients who had never married, divorced, or faced separation through death experienced higher suicidal ideation and engaged in more suicidal attempts ${ }^{7,34-36}$ and that severe relationship conflicts or loss constituted an important indicator of suicide. ${ }^{37}$ As for those living alone, suicidal ideation was high. It appears that less social support leads to higher frustration, higher suicidal ideation, and more suicidal attempts. ${ }^{37,38}$ Patients with a drinking history showed significant suicidal ideation. Previous studies have reported that alcohol or substance abuse is a risk factor of suicidal ideation and leading to higher impulsive suicidal attempts ${ }^{39,40}$ and that dependence on alcohol or substances increases the risk of suicide up to five times. ${ }^{41}$ Recent abuse is an especially salient risk factor of suicide. ${ }^{38} \mathrm{~A}$ prior suicide attempt was associated with significant suicidal ideation. While Hall et al. ${ }^{38}$ suggest that a history of suicide is not a useful factor predicting a suicidal attempt, since $67 \%$ of those people who committed a serious suicidal attempt had done so for the first time, other studies arrive at the opposite conclusion. ${ }^{42,43}$ In this study, patients whose family members committed suicide showed significantly higher suicidal ideation. This supports the view that having a parent or relative who committed suicide increased suicidal ideation or the risk of attempting suicide. ${ }^{44}$ However, Hall et al. ${ }^{38}$ showed that having a family 
HY Choi et al.

Table 1. Socio-demographic and clinical variables of patients with and without significant suicidal ideation

\begin{tabular}{|c|c|c|c|c|c|}
\hline & \multicolumn{2}{|c|}{$\begin{array}{l}\text { With significant suicidal ideation }{ }^{\mathrm{a}} \\
\qquad(\mathrm{N}=121)\end{array}$} & \multicolumn{2}{|c|}{$\begin{array}{l}\text { Without significant suicidal ideation } \\
\qquad(\mathrm{N}=206)\end{array}$} & \multirow[b]{2}{*}{$\mathrm{p}$} \\
\hline & Mean & $\pm \mathrm{SD}$ & Mean & $\pm \mathrm{SD}$ & \\
\hline \multirow[t]{2}{*}{ Age (yr) } & 37.07 & 13.18 & 40.19 & 12.16 & $0.0306^{*}$ \\
\hline & $\mathrm{N}$ & $\%$ & $\mathrm{~N}$ & $\%$ & \\
\hline Gender & & & & & 0.9806 \\
\hline Male & 48 & 39.67 & 82 & 39.18 & \\
\hline Female & 73 & 60.33 & 124 & 60.19 & \\
\hline Education & & & & & $0.0275^{*}$ \\
\hline$<$ High school & 25 & 20.66 & 24 & 11.65 & \\
\hline$\geq$ High school & 96 & 79.34 & 182 & 88.35 & \\
\hline Employment & & & & & $0.0102^{*}$ \\
\hline Employed & 42 & 34.71 & 89 & 43.20 & \\
\hline Unemployed & 38 & 31.40 & 35 & 16.99 & \\
\hline Retired, housewife, student & 41 & 33.88 & 82 & 39.81 & \\
\hline Marital status & & & & & $0.0232^{*}$ \\
\hline Married & 53 & 43.80 & 117 & 56.80 & \\
\hline Never married, divorced, separated & 68 & 20.80 & 89 & 43.20 & \\
\hline Living with family & & & & & $0.0273^{*}$ \\
\hline Yes & 97 & 80.17 & 186 & 90.29 & \\
\hline No & 21 & 17.36 & 16 & 7.70 & \\
\hline Other & 3 & 2.48 & 4 & 1.94 & \\
\hline Income ( $W$, million) & & & & & $0.0132^{*}$ \\
\hline$\leq 2$ & 79 & 65.29 & 102 & 49.51 & \\
\hline $2-5$ & 32 & 26.45 & 70 & 33.98 & \\
\hline $5 \leq$ & 10 & 8.26 & 34 & 16.50 & \\
\hline Religion & & & & & 0.38 \\
\hline None & 60 & 49.59 & 81 & 39.32 & \\
\hline Christian & 40 & 33.06 & 81 & 39.32 & \\
\hline Buddhism & 8 & 6.61 & 22 & 10.68 & \\
\hline Catholicism & 12 & 9.92 & 21 & 10.19 & \\
\hline Etc. & 1 & 0.83 & 1 & 0.49 & \\
\hline Alcohol & & & & & $0.0402^{*}$ \\
\hline Yes & 48 & 39.67 & 59 & 28.54 & \\
\hline No & 73 & 60.33 & 147 & 71.36 & \\
\hline Smoking & & & & & 0.6614 \\
\hline Yes & 32 & 26.45 & 50 & 24.27 & \\
\hline No & 89 & 73.55 & 156 & 75.73 & \\
\hline Medical illness & & & & & 0.5984 \\
\hline Yes & 44 & 36.36 & 69 & 33.50 & \\
\hline No & 77 & 63.64 & 137 & 66.50 & \\
\hline Past psychiatric admission history & & & & & 0.2012 \\
\hline Yes & 34 & 28.10 & 72 & 34.95 & \\
\hline No & 87 & 71.90 & 134 & 65.05 & \\
\hline Past suicide attempts & & & & & $<0.0001^{\dagger}$ \\
\hline Yes & 68 & 56.20 & 22 & 10.68 & \\
\hline No & 53 & 43.80 & 184 & 89.32 & \\
\hline Family psychiatric history & & & & & 0.6849 \\
\hline Yes & 23 & 19.01 & 43 & 20.87 & \\
\hline No & 98 & 80.99 & 163 & 79.13 & \\
\hline Family history of suicide & & & & & $0.0069^{\dagger}$ \\
\hline Yes & 16 & 13.22 & 10 & 4.85 & \\
\hline No & 105 & 86.78 & 196 & 95.15 & \\
\hline
\end{tabular}

a Total scores of Beck Suicidal ideation Scale $\geq 9 .{ }^{*} \mathrm{p}<0.05,{ }^{\dagger} \mathrm{p}<0.01$. SD: standard deviation 
Table 2. Logistic regression analysis of anxiety symptoms and significant suicidal ideation

\begin{tabular}{cccc}
\hline Anxiety & Model 1 unadjusted OR (95\% CI) & Model 2 adjusted OR (95\% CI) & Model 3 adjusted OR (95\% CI) \\
\hline Beck anxiety inventory & $1.071^{*}(1.051-1.092)$ & $1.071^{*}(1.047-1.095)$ & $1.021(0.990-1.053)$ \\
State anxiety inventory & $1.080^{*}(1.058-1.103)$ & $1.074^{*}(1.048-1.101)$ & $1.014(0.981-1.048)$ \\
Trait anxiety inventory & $1.111^{*}(1.082-1.141)$ & $1.107^{*}(1.074-1.140)$ & $1.059^{*}(1.019-1.100)$ \\
\hline
\end{tabular}

Model 1: univariate logistic regression analysis, Model 2: multivariate logistic regression analysis includes the following covariates; age, education, employment, married, living with family, income, alcohol, history of past suicide attempts, family history of suicide, Model 3: multivariate logistic regression analysis includes the following covariates; age, education, employment, married, living with family, income, alcohol, history of past suicide attempts, family history of suicide, depressive symptoms. ${ }^{*}$ p $<0.001$. OR: odds ratio, CI: confidence interval

member who attempted or committed suicide is not a significant risk factor of suicide. De Leo et al. ${ }^{39}$ reported that only $10 \%$ of people who attempted suicide are influenced by a family member's suicidal attempt but that suicidal attempts increase markedly when an acquaintance died by suicide; in this case, such an act may be contagious and become a behavioral model for other people. A family history of suicide probably indicated an inherited tendency, passed on through shared biologic vulnerabilities or family environments.

Unlike some studies, we found no relation of gender to increased suicidal ideation. Some earlier studies argue that females showed higher suicidal ideation ${ }^{34,35}$ and more suicidal behaviors than males. ${ }^{45}$ However, males tended to have a higher risk of suicide than females, since the former were inclined to employ more deadly methods and were more determined to commit suicide. ${ }^{46}$ However, Weissman et al. ${ }^{47}$ suggest that while females in the United States and Europe tend to commit suicide more, no such difference existed in India and Poland, indicating that suicidal attempts may be linked to cultural differences rather than gender-related behaviors. Therefore, it is necessary to study into cultural or social contexts, as well as gender differences. Religion had no significant correlation with increased suicidal ideation. Religion is not an important predicting factor in serious suicidal attempters ${ }^{38}$ and some reports indicate that religious belief or behaviors decrease suicidal attempts. ${ }^{48}$ Medical illness, smoking, past hospitalization in psychiatric wards, or a family psychiatric history had no correlation with significant suicidal ideation either.

This study revealed the relationship between suicidal ideation and anxiety symptoms. When variables related to significant suicidal ideation were adjusted, anxiety symptoms contributed to the increase of suicidal ideation. Moreover, the association between trait anxiety and significant suicidal ideation remained after adjustment for depressive symptoms. These findings are consistent with the contention of a previous study that while both state and trait anxiety are risk factors for suicidal behavior in adolescents, only the latter is relatively independent of depression in its influence on suicidal behavior. $^{49}$
Spielberger ${ }^{26}$ defines trait anxiety as an individual's predisposition to respond and state anxiety as a transitory emotion characterized by physiological arousal and consciously perceived feelings of apprehension, dread, and tension. ${ }^{50}$ Trait anxiety is a potential energy that is characteristically not influenced by psychological tension under particular circumstances. Apter et al. ${ }^{51}$ suggested that trait anxiety acts as an attenuator of violence directed outwards and an augmenter of violence directed inward. They contend that trait rather than state anxiety has higher correlations with risks of suicide and violence. The finding that trait anxiety remained as a risk factor after controlling for variables influencing significant suicidal ideation suggests that anxiety linked to an individual's character contributes more to the increase of suicidal ideation than anxiety influenced by external factors. Thus, trait anxiety is not simply secondary states arising from depression or other comorbidities. A previous study suggested the possible value of anxiety symptoms (panic attack, psychic anxiety, psychomotor agitation, global insomnia) as precursors of suicide and target symptoms for vigorous treatment efforts. ${ }^{52}$ Anxiety is frequently found in mental disorders other than anxiety disorder. Actually, it is more common than anxiety disorder, which suggests the possibility that previous studies that have only dealt with anxiety disorders, have underestimated anxiety symptoms when evaluating the risk of suicide.

While mood and anxiety disorders are important risk factors of suicidal ideation, mental disorders are strong predicting factors of it. Earlier investigations argue that suicidal ideation in the absence of a plan or an attempt is negatively related to the subsequent risk of a suicide plan and attempt ${ }^{36}$ and that the relative magnitudes of the different types of disorders vary in a progression to suicide attempts. ${ }^{53}$ However, one study affirms that the risk of suicidal plans and attempts was highest within the first year of suicidal ideation; specifically, $60 \%$ of the transition from suicidal ideation to suicidal attempts occurred in this time frame. ${ }^{7}$ Overall, these studies suggest that the evaluation of suicidal ideation is crucial in preventing suicide.

As for the limits of this study, first, the subjects were patients from only one university hospital and therefore reflect- 
ed local characteristics or those of patients choosing the hospital. The sample number was also small and does not represent all mental patients. In addition, it was conducted only with outpatients. Second, the samples were not randomly collected. An analysis of biases for patients who did not participate in the study or who failed to complete the questionnaire and were thus excluded did not take place. In the future, larger randomized studies, including those on hospitalized patients with severe suicidal ideation or more risk factors of suicide, are necessary. Third, it was based on self-reported questionnaires, which impose real limits on the evaluations of objective symptoms; at the same time, recall biases and denials must be considered. In further research it needs to assess by clinician rating scales. Forth, we used a cutoff point of BSI scores of 9 or above to classify significant suicidal ideation, because the level of suicidal ideation was considered significantly higher than in the same age group at a score of 9 or above in a previous study. ${ }^{33}$ In retrospect, this cutoff value may something high. ${ }^{16}$ However, we used questionnaires with verified validity and reliability, and cutoff point of 9 that has actually used in clinical practice for assessing suicidal ideation in Korea, Fifth, we could not perform a sensitivity analysis before study. Although we considered establishing the cutoff value using the receiver operating characteristic value, with the suicidal-attempt history as the state variable, we thought that as the time point at which suicide would be assessed using BSI was the past one week, there would be a time gap, and this gap would be another bias. Finally, the study was cross-sectional and the causation between suicidal ideation and anxiety was not identified. Therefore, long-term transitional studies will be necessary in the future.

Despite these limitations, this study demonstrated that anxiety symptoms are an independent risk factor for significant suicidal ideation. Anxiety symptoms are frequently found among patients with mental disorders and can be easily measured. Therefore, clinicians may use anxiety symptoms as a screening marker when evaluating suicide ideation and suicidal risk. Further studies with larger randomized samples must clarify the relationship between anxiety symptoms and suicidal ideation.

\section{REFERENCES}

1. Korean Statistical Information System. Change in Populations, Statistics 2009. Available at: http://kostat.go.kr/. Accessed September 9, 2010.

2. Jeon HJ, Lee JY, Lee YM, Hong JP, Won SH, Cho SJ, et al. Lifetime prevalence and correlates of suicidal ideation, plan, and single and multiple attempts in a Korean Nationwide Study. J Nerv Ment Dis 2010;198:643-646.

3. Murray CJ, Lopez AD. Alternative projections of mortality and disability by cause 1990-2020: Global burden of disease study. Lancet 1997;349:1498-1504.

4. Mathers CD, Loncar D. Projections of global mortality and burden of disease from 2002 to 2030. PLoS Med 2006;3:e442.

5. Phillips DP, Ruth TE. Adequacy of official suicide statistics for scientific research and public policy. Suicide Life Treat Behav 1993;23:307-319.

6. Morgan HG, Stanton R. Suicide among psychiatric in-patients in a changing clinical scene. Suicidal ideation as a paramount index of short-term risk. Br J Psychiatry 1997;171:561-563.

7. Nock MK, Borges G, Bromet EJ, Alonso J, Angermeyer M, Beautrais $\mathrm{A}$, et al. Cross-national prevalence and risk factors for suicidal ideation, plans and attempts. Br J Psychiatry 2008;192:98-105.

8. Kessler RC, Berglund P, Demler O, Jin R, Merikangas KR, Walters EE. Lifetime prevalence and age-of-onset distributions of DSM-IV disorders in the National Comorbidity Survey Replication. Arch Gen Psychiatry 2005;62:593-602.

9. Lepine JP. The epidemiology of anxiety disorders: prevalence and societal costs. J Clin Psychiatry 2002;63(Suppl 14):4-8.

10. Alonso J, Lepine JP; ESEMeD/MHEDEA 2000 Scientific Committee. Overview of key data from the European Study of the Epidemiology of Mental Disorder (ESEMeD). J Clin Psychiatry 2007;68(suppl 2):3-9.

11. Sareen J, Cox BJ, Afifi TO, de Graaf R, Asmundson GJ, ten Have M, et al. Anxiety disorders and risk for suicidal ideation and suicide attempts: a population-based longitudinal study of adults. Arch Gen Psychiatry 2005;62:1249-1257.

12. Goodwin RD, Roy-Byrne P. Panic and suicidal ideation and suicide attempts: results from the National Comorbidity Survey. Depress Anxiety 2006;23:124-132.

13. Pilowsky DJ, Olfson M, Gameroff MJ, Wickramaratne P, Blanco C, Feder A, et al. Panic disorder and suicidal ideation in primary care. Depress Anxiety 2006;23:11-16.

14. Bolton JM, Cox BJ, Afifi TO, Enns MW, Bienvenu OJ, Sareen J. Anxiety disorders and risk for suicide attempts: findings from the Baltimore Epidemiologic Catchment area follow-up study. Depress Anxiety 2008; 25:477-481.

15. Nakagawa A, Grunebaum MF, Sullivan GM, Currier D, Ellis SP, Burke $\mathrm{AK}$, et al. Comorbid anxiety in bipolar disorder: dose it have an independent effect on suicidality? Bipolar Disord 2008;10:530-538.

16. Sokero TP, Melartin TK, Rytsala HJ, Leskela US, Lestela-Mielonen PS, Isometsa ET. Suicidal ideation and attempts among psychiatric patients with major depressive disorder. J Clin Psychiatry 2003;64:1094-1100.

17. Pfeiffer PN, Ganoczy D, Ilgen M, Zivin K, Valenstein M. Comorbid anxiety as a suicide risk factor among depressed veterans. Depress Anxiety 2009;26:752-757.

18. Olfson M, Broadhead WE, Weissman MM, Leon AC, Farber L, Hoven C, et al. Subthreshold psychiatric symptoms in a primary care group practice. Arch Gen Psychiatry 1996;53:880-886.

19. Hanel G, Henningsen P, Herzog W, Sauer N, Schaefert R, Szecsenyi J, et al. Depression, anxiety, and somatoform disorders: vague or distinct categories in primary care? Results from a large cross-sectional study. J Psychosom Res 2009;67:189-197.

20. Diefenbach GJ, Woolley SB, Goethe JW. The association between selfreported anxiety symptoms and suicidality. J Nerv Ment Dis 2009;197: 92-97.

21. Ghaziuddin N, King CA, Naylor MW, Ghaziuddin M. Anxiety contributes to suicidality in depressed adolescents. Depress Anxiety 2000;11: 134-138.

22. Ringbäck Weitoft G, Rosen M. Is perceived nervousness and anxiety a predictor of premature mortality and severe morbidity? A longitudinal follow up of the Swedish survey of living conditions. J Epidemiol Community Health 2005;59:794-798.

23. Busch KA, Fawcett J, Jacobs DG. Clinical correlates of inpatient suicide. J Clin Psychiatry 2003;64:14-19.

24. Fawcett J. Treating impulsivity and anxiety in the suicidal patient. Ann N Y Acad Sci 2001:932;94-102.

25. Beck AT, Epstein N, Brown G, Steer RA. An inventory for measuring clinical anxiety: psychometric properties. J Consult Clin Psychol 1988;56:893-897. 
26. Spielberger CD, Gorsuch RL. Manual for the State-Trait Anxiety Inventory (Form Y) : "Self-Evaluation Questionnaire”. Palo Alto, CA: Consulting Psychologist Press; 1983.

27. Yook SP, Kim ZS. A clinical study on the Korean version of Beck Anxiety Inventory: comparative study of patient and non-patient. Korean J Clin Psychol 1997;16:185-197.

28. Kim JT. Relationship between Trait Anxiety and Sociality. Master's Thesis. Seoul: College of Medicine, Korea University; 1978.

29. Beck AT, Ward CH, Mendelson M, Mock J, Erbaugh J. An inventory for measuring depression. Arch Gen Psychiatry 1961;4:561-571.

30. Lee YH, Song JY. A Study of the reliability and the validity of the BDI, SDS and MMPI-D scales. Korean J Clin Psychol 1991;10:98-113.

31. Beck AT, Kovacs M, Weissman A. Assessment of suicidal intention: the Scale for Suicide Ideation. J Consult Clin Psychol 1979;47:343-352.

32. Cochrane-Brink KA, Lofchy JS, Sakinofsky I. Clinical rating scales in suicide risk assessment. Gen Hosp Psychiatry 2000;22:445-451.

33. Shin MS. An Empirical Study of the Mechanism of Suicide: Validation of the Scale for Escape from the Self. Doctorial Dissertation. Seoul: Yonsei University; 1993.

34. Bernal M, Haro JM, Bernert S, Brugha T, de Graaf R, Bruffaerts R, et al. Risk factors for suicidality in Europe: results from the ESEMED study. J Affect Disord 2007;101:27-34.

35. Kessler RC, Berglund P, Borges G, Nock M, Wang PS. Trends in suicide ideation, plans, gestures, and attempts in the United States, 1990-1992 to 2001-2003. JAMA 2005;293:2487-2495.

36. Borges G, Angst J, Nock MK, Ruscio AM, Kessler RC. Risk factors for the incidence and persistence of suicide-related outcomes: a 10-year follow-up study using National Comorbidity Surveys. J Affect Disord 2008;105:25-33.

37. Thomas HV, Crawford M, Meltzer H, Lewis G. Thinking life is not worth living. A population survey of Great Britain. Soc Psychiatry Psychiatr Epidemiol 2002;37:351-356.

38. Hall RC, Platt DE, Hall RC. Suicide risk assessment: a review of risk factors for suicide in 100 patients who made severe suicide attempts. Evaluation of suicide risk in a time of managed care. Psychosomatics 1999;40:18-27.

39. De Leo D, Cerin E, Spathonis K, Burgis S. Lifetime risk of suicide ideation and attempts in an Australian community: prevalence, suicidal process, and help-seeking behaviour. J Affect Disord 2005;86:215-224.

40. Marzuk PM, Mann JJ. Suicide and substance abuse. Psychiatric annals 1998;18:639-645.

41. Roy A, Lamparski D, DeJong J, Moore V, Linnolia M. Characteristics of alcoholics who attempt suicide. Am J Psychiatry 1990;147:761-765.

42. Moscicki EK. Identification of suicide risk factors using epidemiologic studies. Psychiatr Clin North Am 1997;20:499-517.

43. Miles CP. Conditions predisposing to suicide: a review. J Nerv Ment Dis 1977;164:231-246.

44. Statham DJ, Heath AC, Madden PA, Bucholz KK, Bierut L, Dinwiddie $\mathrm{SH}$, et al. Suicidal behaviour: an epidemiological and genetic study. Psychol Med 1998;28:839-855.

45. Petronis KR, Samuels JF, Moscicki EK, Anthony JC. An epidemiologic investigation of potential risk factors for suicide attempts. Soc Psychiatry Psychiatr Epidemiol 1990;25:193-199.

46. Nock MK, Kessler RC. Prevalence of and risk factors for suicide attempts versus suicide gestures: analysis of the National Comorbidity survey. J Abnorm Psychol 2006;115:616-623.

47. Weissman MM. The Epidemiology of suicide attempts, 1960 to 1971. Arch Gen Psychiatry 1974;30:737-746.

48. Dervic K, Oquendo MA, Grunebaum MF, Ellis S, Burke AK, Mann JJ. Religious affiliation and suicidal attempt. Am J Psychiatry 2004;161: 2303-2308.

49. Ohring R, Apter A, Ratzoni G, Weizman R, Tyano S, Plutchik R. State and trait anxiety in adolescent suicide attempters. J Am Acad Child Adolesc Psychiatry 1996;35:154-157.

50. Spielberger CD. Anxiety and Behaviour. New York: Academic Press; 1966.

51. Apter A, Plutchik R, van Praag HM. Anxiety, impulsivity and depressed mood in relation to suicidal and violent behavior. Acta Psychiatr Scand 1993;87:1-5.

52. Fawcett J, Scheftner WA, Fogg L, Clark DC, Young MA, Hedeker D, et al. Time-related predictors of suicide in major affective disorder. Am J Psychiatry 1990;147:1189-1194.

53. Nock MK, Hwang I, Sampson N, Kessler RC, Angermeyer M, Beautrais A, et al. Cross-national analysis of the associations among mental disorders and suicidal behavior: findings from the WHO World Mental Health Surveys. PLoS Med 2009;6:e1000123. 